Article

\title{
Effect of Cold Storage and Reheating of Parboiled Rice on Postprandial Glycaemic Response, Satiety, Palatability and Chewed Particle Size Distribution
}

\author{
Louise Weiwei Lu ${ }^{1,2, *}$, Bernard Venn ${ }^{3}$, Jun Lu ${ }^{4}$, John Monro ${ }^{5}$ and Elaine Rush ${ }^{1}$ \\ 1 School of Sport and Recreation, Faculty of Health and Environmental Sciences, \\ Auckland University of Technology, Auckland 1010, New Zealand; elaine.rush@aut.ac.nz \\ 2 Human Nutrition Unit (HNU), School of Biological Sciences, University of Auckland, \\ Auckland 1010, New Zealand \\ 3 Department of Human Nutrition, University of Otago, Dunedin 9016, New Zealand; \\ Bernard.venn@otago.ac.nz \\ 4 School of Science, and School of Interprofessional Health Studies, Faculty of Health and Environmental \\ Sciences, Auckland University of Technology, Auckland 1010, New Zealand; jun.lu@aut.ac.nz \\ 5 The New Zealand Institute for Plant \& Food Research, Palmerston North 4474, New Zealand; \\ john.monro@plantandfood.co.nz \\ * Correspondence: louise.lu@auckland.ac.nz or louise.lu@aut.ac.nz or louiseweiweilu@me.com; \\ Tel.: +64-21-254-6486
}

Received: 24 February 2017; Accepted: 5 May 2017; Published: 10 May 2017

\begin{abstract}
Background: Globally, hot cooked refined rice is consumed in large quantities and is a major contributor to dietary glycaemic load. This study aimed to compare the glycaemic potency of hot- and cold-stored parboiled rice to widely available medium-grain white rice. Method: Twenty-eight healthy volunteers participated in a three-treatment experiment where postprandial blood glucose was measured over $120 \mathrm{~min}$ after consumption of $140 \mathrm{~g}$ of rice. The three rice samples were freshly cooked medium-grain white rice, freshly cooked parboiled rice, and parboiled rice stored overnight at $4{ }^{\circ} \mathrm{C}$. All rice was served warm at $65{ }^{\circ} \mathrm{C}$. Chewing time was recorded. Results: incremental area under the curve (iAUC) of the control rice, freshly cooked medium-grain white rice, was the highest: 1.7-fold higher $(1.2,2.6)$ than reheated parboiled rice $(p<0.001)$ and 1.5-fold higher $(1.0,2.2)$ than freshly cooked parboiled rice $(p=0.001)$. No significant difference in postprandial glycaemic response was observed between freshly cooked and reheated parboiled rice samples $(p=0.445)$. Chewing time for $10 \mathrm{~g}$ cold-stored parboiled rice was $6 \mathrm{~s} \mathrm{(25 \% )} \mathrm{longer} \mathrm{and} \mathrm{was} \mathrm{considered} \mathrm{more}$ palatable, visually appealing and better tasting than freshly cooked medium-grain (all $p<0.05$ ). Conclusions: For regular consumers of rice, reheating cooked rice after cold storage would lower the dietary glycaemic load and, in the long term, may reduce the risk for type 2 and gestational diabetes. More trials are needed to identify the significance.
\end{abstract}

Keywords: parboiled rice; medium-grain white rice; cold-stored; reheating; blood glucose concentration chewing time; satiety; palatability

\section{Introduction}

Globally, the consumption of rice, which currently provides the majority of daily energy intake and carbohydrate for at least half of the world's population [1], has been increasing. Since the Joint FAO/WHO Expert Consultation on Carbohydrates in Human Nutrition in April 1997 [2], there has been increased understanding of the diverse physiological roles that carbohydrates have on the rate and extent of digestion in the gut and the relationship between dietary carbohydrates and 
various non-communicable diseases, including hyperglycaemia, insulin resistance, obesity, metabolic syndrome and type 2 diabetes [3].

The metabolic quality of carbohydrate sources such as rice may be directly determined by the effect on biomarkers of carbohydrate metabolism, such as glycaemic response (i.e., postprandial blood glucose concentration). The key determinants of the postprandial blood glucose response are the amount, rate and extent of carbohydrate digestion [4], insulin secretory response [5] and gastric emptying [6,7]. The extent of digestion, and thus the glycaemic response, are determined by the particle size of the food, the cooking method, the size of the mouthful, the extent of chewing and digestion that takes place in the mouth, and the physical and chemical properties of the starch [8,9].

One measure of a healthier cooked rice meal would be reduction of the glycaemic load (GL, i.e., slower and lower sustained release of glucose) by providing a lower proportion of rapidly digestible starch (RDS, starch that can be digested within $20 \mathrm{~min}$ following ingestion). This means higher proportions of slowly digestible starch (SDS, starch that can be digested between 20 and $180 \mathrm{~min}$ following ingestion) and resistant starch (RS, starch that can resist digestion for up to $180 \mathrm{~min}$ following ingestion).

Cooling cooked rice to low temperatures by refrigeration transforms gelatinised rice starch from an amorphous state to a more ordered state (i.e., crystalline state) that persists on reheating. This crystallised starch form can resist enzymatic degradation in the small intestine for up to three hours [10] and spontaneously lower the concentration of digestible starch in cooked rice [11]. Previous in vitro digestion studies have also shown that freshly cooked warm rice was digested more rapidly than cold-stored and reheated rice and minced-reheated parboiled rice was more resistant to digestion [12]. Three previous studies, by Wolever [13], Larsen [14], and Chitra [15], have investigated the commercially obtained parboiled rice products (processed by modernised parboiling process) and found lower glycaemic response in the freshly prepared parboiled rice samples compared with non-parboiled, but satiety was not measured in these studies. Furthermore, the glycaemic response of cooked parboiled rice after the cold storage and reheating process has not been investigated.

Rice grains are consumed as whole, therefore, the particle size reduction solely depends on mastication habit (i.e., chewing time and style). Mastication habits vary widely among individuals but show relatively consistent patterns within an individual when a single food has been tested [16]. Previous in vitro experiments [12] and an in vivo study [16] reported that particle size decrease exposes more surface area to digestive enzymes, resulting in an increase in the rate of digestion. The effect of habitual mastication and the degree of particle size reduction on glucose responses of a single food has been investigated in previous studies [16-18]. The degree of particle size reduction and its impact on glucose response among rice varieties have not been investigated previously.

It was hypothesised that cooking followed by cold storage at $4{ }^{\circ} \mathrm{C}$ for $24 \mathrm{~h}$ and subsequent reheating to $65^{\circ} \mathrm{C}$ for $15 \mathrm{~min}$, in accordance with safe practice [19], would result in parboiled rice inducing a significantly lower glycaemic response than both freshly prepared medium-grain white rice and parboiled rice. A secondary hypothesis was that the cold storage and reheating process would significantly increase the chewing time, reduce the chewed particle size, and increase the glycaemic response. Moreover, consumption of reheated parboiled rice would enhance satiety and reduce palatability.

\section{Materials and Methods}

\subsection{Study Design}

Twenty-eight healthy subjects participated in a cross-over study randomised for order of the three treatments on three different days. The three treatments were freshly cooked medium-grain white rice (Control, Oryza sativa japonica, Australia imported raw medium-grain white rice (SunRice ${ }^{\circledR}$, Leeton, Australia)), freshly cooked parboiled rice (Test Rice 1, Oryza sativa indica, produced and imported from Thailand (RealRice ${ }^{\circledR}$, Thailand imported)), and reheated parboiled rice (Test Rice 2, Oryza sativa 
indica, produced and imported from Thailand (RealRice ${ }^{\circledR}$, Thailand imported)). The primary outcome was postprandial blood glucose concentration trajectory. Secondary outcomes were chewing time, chewed particle size distributions, satiety and palatability responses. The design of the primary experiment was based on glycaemic index (GI) methodology but used a one-cup serving of rice [20] to reflect the quantity of rice usually eaten rather than a standard dose of carbohydrate.

The required sample size was estimated based on the review by Venn and Green [21] and the rice GI data from the Sydney University GI database. To detect a $20 \%$ reduction in postprandial blood glucose incremental area under the curve (iAUC) among differences between rice samples, and setting $\alpha$-error to 0.05 and $\beta$-error to 0.90 , it was estimated that 25 participants were required if each rice sample was tested once. Similarly, based on several previous satiety investigations using visual analogue scales (VAS) [22] it was determined that to achieve a practically significant difference in satiety of $20 \%$ with $80 \%$ power would require a sample size of 13 participants.

\subsection{Participants}

Adult participants were recruited from the Dunedin, New Zealand, as a convenient sample. Volunteers were recruited using advertisements, flyers, information sheets, notices and Internet postings and assessed for eligibility using an online survey (Survey Monkey, Palo Alto, CA, USA). Inclusion criteria included age between 18 and 45 years living in Dunedin. Exclusion criteria included self-reported smoker, pregnancy, being diagnosed with long-term illness (i.e., metabolic disorder, cancer, cardiovascular diseases), currently on long-term medication, and having abnormal fasting blood glucose (fasting finger prick blood glucose over $6.0 \mathrm{mmol} / \mathrm{L}$ [23]). Eligible persons were screened for body mass index (BMI): heights $(\mathrm{m})$ and weights $(\mathrm{kg})$ were measured using Segmental Body Composition Analyser (BC-418, Tokyo, Japan). Volunteers with BMI over $25.0 \mathrm{~kg} / \mathrm{m}^{2}$ were categorised as overweight or obese, and between 18.0 and $25.0 \mathrm{~kg} / \mathrm{m}^{2}$ as normal. To control for body mass index (BMI) effects on glycaemic responses and to broaden generalisability, around half of the participants were screened for normal weight and half for being overweight or obese (WHO criteria). All volunteers were screened for fasting finger prick glucose (using a HemoCue reader, HemoCue ${ }^{\circledR}$ $\mathrm{Hb} 201$ System, Ängelholm, Sweden). Thirty participants were eligible and recruited. Two participants later withdrew due to other commitments.

This study was conducted according to the guidelines of the human ethics committees of the University of Otago and the Auckland University of Technology (AUT). Both university ethics committees approved all procedures involving human participants. Ethical approval for the study was obtained from the University of Otago Ethics Committee $(12 / 333)$ and the AUT Ethics Committee (EA13/05).

\subsection{Rice Treatments}

Three $1 \mathrm{~kg}$ bags of medium-grain white and two $2 \mathrm{~kg}$ bags of parboiled long-grain rice were purchased from New Zealand Dunedin supermarkets. Both rice products were from the same batch to avoid inter-batch variation. The rice was cooked following the instructions provided by the rice manufacturers to best reproduce the habitual cooking procedure. The rice-to-water ratio was 3:4.5 for medium-grain white rice using standard measuring cups (Farberware ${ }^{\circledR}$ Classic Measuring Cup, $1 \mathrm{cup}=200 \mathrm{~g}$ rice or $250 \mathrm{~mL}$ of tap water) and 3:7 for parboiled rice. Rice samples were cooked to full gelatinisation in an automatic rice cooker (Tefal ${ }^{\circledR}$ R07, Rumilly, France) at room temperature. The freshly cooked medium-grain rice (Control) and freshly cooked parboiled rice (Test Rice 1) were checked for temperature (around $65^{\circ} \mathrm{C}$ ) and then served to participants in preheated bowls within 10 min following cooking.

For cold-stored and reheated parboiled rice (Test Rice 2), the rice sample was firstly cooked to full gelatinisation as for Test Rice 1. Approximately $140 \mathrm{~g}$ of freshly cooked parboiled long-grain white rice was weighed using electronic scales (Sartorius ${ }^{\circledR}, \mathrm{CP} 4202 \mathrm{~S}$, Goettingen, Germany) and placed into a shallow bowl ( $4 \mathrm{~cm}$ deep, pre-cooled to $4{ }^{\circ} \mathrm{C}$ in the refrigerator) to ensure instant cooling. Plastic food 
wrap was wrapped around the bowl to prevent moisture loss. The sealed rice bowls were placed in the refrigerator for rapid cooling to $4{ }^{\circ} \mathrm{C}$ and for 24-h storage. The temperature of the cooled rice was checked three times: at three hours, six hours and twenty four hours after refrigeration, using a clean wiped thermometer. Before consumption, the bowls were removed from the refrigerator and reheated in a convection microwave oven (Sharp ${ }^{\circledR}, \mathrm{R} 99$, Osaka, Japan) at $1000 \mathrm{~W}$ power until the temperature after stirring reached $65^{\circ} \mathrm{C}$.

\subsection{Study Visits}

Participants were randomly allocated a rice sample of either Control Rice, Test Rice 1, or Test Rice 2 in a repeated randomised cross-over design. The randomisation was determined using a random number generator. Each rice sample was consumed on separate days one week apart from the previous study day to minimise any possible ordering effect [24]. Each day, participants reported at 6 a.m., after a $10 \mathrm{~h}$ overnight fast, to the Glycaemic Index Laboratory, Science Building One, University of Otago, Dunedin, New Zealand. Participants were advised to continue their usual daily activities without engaging in vigorous exercise or consuming food containing high fat, high sugar, or alcohol during the study period.

In each study visit, participants completed a series of three separate tests on one rice product: blood glucose responses test, satiety and palatability VAS, and chewing test. Fasting blood glucose was measured twice. Participants then consumed the rice sample $(140 \mathrm{~g})$ and a glass of water within 15 min following the fasting blood glucose measurement. Participants were asked to consume the rice samples at their normal chewing speed. Postprandial blood glucose concentrations were measured at 0, 15, 30, 45, 60, 90 and 120 min (HemoCue analysers; HemoCue ${ }^{\circledR} \mathrm{Hb} 201$ System, Aktiebolaget Leo, Helsingborg, Sweden). Analysers were calibrated using an instrument-matched calibration cuvette, and checked for accuracy and reliability using three concentrations of control solutions $(2.0 \mathrm{mmol} / \mathrm{L}$, $4.5 \mathrm{mmol} / \mathrm{L}$ and $8.0 \mathrm{mmol} / \mathrm{L}$ ) provided by the HemoCue manufacturer.

Satiety was recorded by participants at 0 (before rice consumption), 30, 60, 90 and 120 min using a modified version of a validated VAS. Participants were provided with eight satiety questions ("How hungry do you feel?", "How satisfied do you feel?". "How full do you feel?", “How much do you think you can eat?", "Would you like to eat something sweet?", "Would you like to eat something salty?", "Would you like to eat something savoury?", "Would you like to eat something fatty?"). Participants were asked to rate five palatability questions on the visual appeal, smell, taste, aftertaste and overall palatability within $5 \mathrm{~min}$ immediately after rice consumption. For each question, participants were asked to mark their relative response on the unmarked visual analogue score line $(10 \mathrm{~cm}$ in length). After completion of each questionnaire, it was turned face down on the desk to prevent participants from reviewing the previous results. The VAS score was analysed by measuring the length in $\mathrm{cm}$ $( \pm 0.1 \mathrm{~cm})$ from the left end of the scale to the mark.

At the end of the testing (120 min), participants were given a tablespoonful of rice sample $(10.6 \pm 0.1 \mathrm{~g})$ and asked to chew it at their normal chewing speed as they did previously in the glucose response test. Instead of swallowing, they were asked to expectorate the rice into a labelled container. Time (s) spent on chewing was recorded by the researcher. A sip of lukewarm water was then given to the participants to rinse the mouth and then expectorate the remaining chewed particles in the mouth into the same container. They were asked to repeat the chewing test if they accidently swallowed part of the rice sample. Expectorated samples were washed through a set of three stainless steel laboratory sieves with mesh apertures of $2000 \mu \mathrm{m}, 1400 \mu \mathrm{m}$ and $425 \mu \mathrm{m}$. The rice particles retained on the sieves and in the final wash were carefully washed (to eliminate the salivary $\alpha$-amylase residues), collected and placed into metal dishes for drying in a convection oven at $70{ }^{\circ} \mathrm{C}$ and weighed twice at 24 and $48 \mathrm{~h}$ to ensure complete drying. Non-expectorated duplicate samples of cooked rice were used to determine moisture content. The particle size of the rice masticated by the 28 individuals was weighed into four ranges (over $2000 \mu \mathrm{m}$, between $2000 \mu \mathrm{m}$ and $1400 \mu \mathrm{m}$, between $1400 \mu \mathrm{m}$ and $425 \mu \mathrm{m}$, and less than $425 \mu \mathrm{m}$ ). For the weight of the dried sample and the moisture content, the proportions of 
the rice sample that passed through the sieves ("particle diameter $>2000 \mu \mathrm{m}$ ", "particle diameter $\leq 2000 \mu \mathrm{m}$ and $>1400 \mu \mathrm{m}$ ", "particle diameter $\leq 1400 \mu \mathrm{m}$ and $>425 \mu \mathrm{m}$ ", and "particle diameter $\left.\leq 425 \mu \mathrm{m}^{\prime \prime}\right)$ were calculated. For each diameter, the same sieve was used each time to minimise cumulative errors and reduce variability. These particle sizes were chosen based on a previous study carried out in the same laboratory as this investigation [16].

\subsection{Statistical Analysis}

The incremental area under the blood glucose curve (iAUC) and the total area under the curve for each satiety parameter were calculated using the trapezoidal rule [4]. The finger prick blood glucose concentrations and area under the glucose response curve (AUC) were compared among three rice samples by repeated measurement analysis of variance (ANOVA). The chewed particle size distributions, chewing time, satiety, and palatability scores were also analysed by repeated measurement ANOVA. Univariate regression models with a random effect for participants were used to examine the association between the AUC for rice and variables including age, sex, BMI, chewed particle distributions, chewing time, satiety, and palatability scores. The regression analysis was also undertaken with the particle size distribution (\%, the proportion of chewed rice particles) as the dependent variable and the chewing time (s) as an explanatory variable. The comparison for each expectorated rice sample was investigated across four ranges of rice particle size: '>2000 $\mu \mathrm{m}^{\prime}$, ' $<2000$ $\mu \mathrm{m}$ and $>1400 \mu \mathrm{m}^{\prime}$, ' $<1400 \mu \mathrm{m}$ and $>425 \mu \mathrm{m}^{\prime}$, and ' $<425 \mu \mathrm{m}$ '. All statistical analyses were performed using SPSS version 12.0 (SPSS Inc., Chicago, IL, USA).

\section{Results}

\subsection{Participants}

All 28 volunteers completed the three study visits. The participants included 18 females and 10 males, aged 22.1 (95\% CI: 20.0, 24.2) and 25.3 (95\% CI: 20.7, 29.9) years respectively. Twenty participants were European, six were South Asian, and two were Chinese. In the screening session, all participants had normal fasting blood glucose (male, 5.0 (95\% CI: 4.8, 5.2) mmol/L; female, 4.9 (95\% CI: $4.8,5.0) \mathrm{mmol} / \mathrm{L}$ ) according to the World Health Organisation classification (normal fasting blood glucose less than $6.1 \mathrm{mmol} / \mathrm{L}$ ).

By design, half the participants were normal weight $(\mathrm{BMI}<25)$ or overweight including obese (BMI $\geq 25 \mathrm{~kg} / \mathrm{m}^{2}$ ). No significant difference was found between the two BMI groups in fasting blood glucose $(p=0.589)$.

\subsection{Comparison of Glycaemic Response Trajectory and the Incremental Area Under the Blood Glucose Response Curve (iAUC)}

Among all experimental treatments, the fasting blood glucose concentrations were similar prior to consumption of each of the three rice meals (freshly cooked medium-grain white, 4.9 (95\% Confidence Interval (CI): 4.8, 5.1) mmol/L; freshly cooked parboiled rice, 5.0 (95\% CI: 4.8, 5.1) $\mathrm{mmol} / \mathrm{L}$; reheated parboiled rice, $4.8(95 \% \mathrm{CI}: 4.7,5.0) \mathrm{mmol} / \mathrm{L}$; Table 1$)$ and were not significantly different $(\mathrm{F}=1.020$, $p=0.356$ ). (Table 1).

Significant differences were observed in the iAUC for the three rice treatments $(\mathrm{F}=9.555, p<0.001)$. iAUC of the control rice, freshly cooked medium-grain white rice, was the highest: 1.7-fold higher $(1.2,2.6)$ than reheated parboiled rice $(p<0.001)$ and 1.5-fold higher $(1.0,2.2)$ than freshly cooked parboiled rice $(p=0.001)$. (Table 1 , Figure 1$)$. No statistically significant difference in iAUC was found between the reheated and freshly cooked parboiled rice $(p=0.445)$.

This initial faster and prolonged higher glycaemic response for the medium-grain white rice compared to reheated parboiled rice was sustained over $120 \mathrm{~min}$. In contrast, the mean glycaemic response to reheated parboiled rice dropped below $5.0 \mathrm{mmol} / \mathrm{L} 90 \mathrm{~min}$ after consumption finished. (Figure 1) The repeated measures ANOVA test showed that the mean incremental blood glucose 
concentration ( $\mathrm{mmol} / \mathrm{L})$ was significantly lower in reheated parboiled rice compared to freshly cooked medium-grain white rice at $15 \mathrm{~min}(-0.4 \mathrm{mmol} / \mathrm{L}, p=0.015)$, at $45 \mathrm{~min}(-0.5 \mathrm{mmol} / \mathrm{L}, p=0.018)$, at $60 \mathrm{~min}(-0.8 \mathrm{mmol} / \mathrm{L}, p=0.001)$, at $90 \mathrm{~min}(-0.8 \mathrm{mmol} / \mathrm{L}, p<0.001)$, and at $120 \mathrm{~min}(-0.4 \mathrm{mmol} / \mathrm{L}$, $p=0.001)$. With increasing time, there was increasing divergence in the response curves by rice product: from around $15 \%$ (eta $=0.157$ at baseline) to around $46 \%$ (eta $=0.459$ at $90 \mathrm{~min}$ ). The same test showed statistically significant differences between freshly cooked parboiled and freshly cooked medium-grain white rice at $45 \mathrm{~min}(-0.6 \mathrm{mmol} / \mathrm{L}, p=0.050)$, at $60 \mathrm{~min}(-0.7 \mathrm{mmol} / \mathrm{L}, p=0.020)$, at $90 \mathrm{~min}(-0.5 \mathrm{mmol} / \mathrm{L}, p=0.007)$, and at $120 \mathrm{~min}(-0.4 \mathrm{mmol} / \mathrm{L}, p=0.028)$ (Table 1$)$. Overall, no significant difference was found between freshly cooked and reheated parboiled rice (both least significant difference (LSD) and Bonferroni tests $p>0.05$ ).

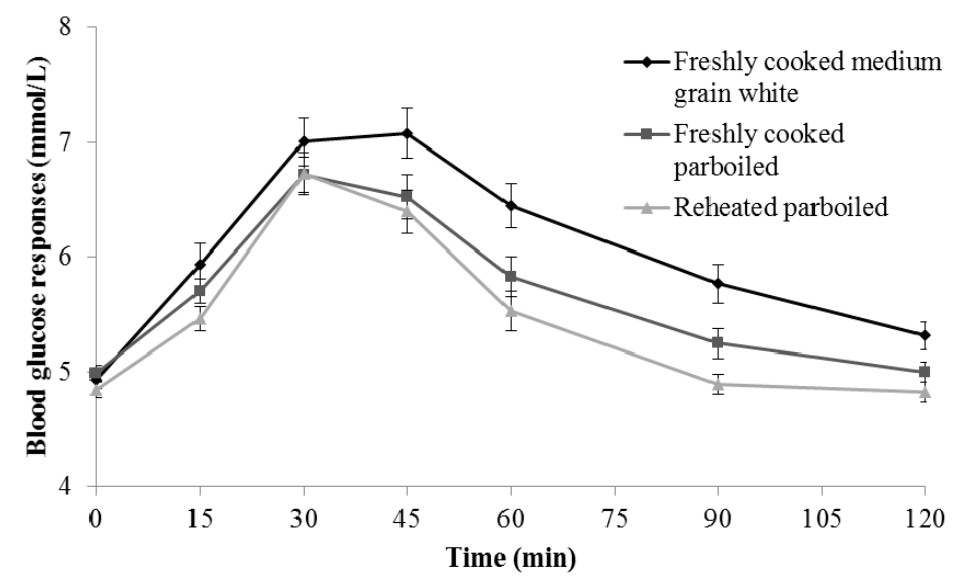

Figure 1. Postprandial blood glucose responses (means \pm standard error) after consuming three rice samples (140 g): Freshly cooked medium-grain white (control), freshly cooked parboiled (Test 1), and reheated parboiled rice (Test 2). Test of homogeneity of variance had $p=0.001$ at $15 \mathrm{~min}$ and 0.014 at $90 \mathrm{~min}$ ).

Table 1. Means of blood glucose responses (mmol/L) at baseline and incremental blood glucose response $(\mathrm{mmol} / \mathrm{L})$ at each time point after consuming three rice samples $(140 \mathrm{~g})$ and the incremental area under the glucose responses curve (iAUC) $(\mathrm{mmol} / \mathrm{L} \cdot \mathrm{min})$.

\begin{tabular}{|c|c|c|c|c|c|c|c|c|c|}
\hline \multicolumn{2}{|c|}{ Rice Samples } & \multirow{2}{*}{$\begin{array}{l}\text { Incremental } \\
\text { Area Under the } \\
\text { Curve (iAUC) } \\
(\mathrm{mmol} / \mathrm{L} \cdot \mathrm{min})\end{array}$} & \multirow{2}{*}{$\begin{array}{c}\begin{array}{c}\text { Baseline } \\
\text { Blood } \\
\text { Glucose }\end{array} \\
(\mathrm{mmol} / \mathrm{L})\end{array}$} & \multicolumn{6}{|c|}{ Incremental Blood Glucose Responses (mmol/L) } \\
\hline $\begin{array}{l}\text { Cooking } \\
\text { Methods }\end{array}$ & $\begin{array}{c}\text { Rice } \\
\text { Products }\end{array}$ & & & $15 \mathrm{~min}$ & $30 \mathrm{~min}$ & $45 \mathrm{~min}$ & $60 \mathrm{~min}$ & $90 \mathrm{~min}$ & $120 \mathrm{~min}$ \\
\hline \multicolumn{10}{|c|}{ Control Rice } \\
\hline $\begin{array}{l}\text { Freshly } \\
\text { cooked }\end{array}$ & $\begin{array}{l}\text { Medium-grain } \\
\text { white }\end{array}$ & $\begin{array}{c}144.7^{\mathrm{a}} \\
(119.8,169.6)\end{array}$ & $\begin{array}{c}4.9 \\
(4.8,5.1)\end{array}$ & $\begin{array}{c}1.0^{\mathrm{a}} \\
(0.7,1.3)\end{array}$ & $\begin{array}{c}2.1 \\
(1.7,2.5)\end{array}$ & $\begin{array}{c}2.1^{\mathrm{a}} \\
(1.7,2.5)\end{array}$ & $\begin{array}{c}1.5^{\mathrm{a}} \\
(1.1,1.9)\end{array}$ & $\begin{array}{c}0.8^{\mathrm{a}} \\
(0.5,1.1)\end{array}$ & $\begin{array}{c}0.4^{\mathrm{a}} \\
(0.1,0.6)\end{array}$ \\
\hline \multicolumn{10}{|l|}{ Test Rice } \\
\hline $\begin{array}{l}\text { Freshly } \\
\text { cooked }\end{array}$ & Parboiled & $\begin{array}{c}94.9^{\mathrm{b}} \\
(75.5,114.4)\end{array}$ & $\begin{array}{c}5.0 \\
(4.8,5.1)\end{array}$ & $\begin{array}{c}0.7 \\
(0.5,0.9)\end{array}$ & $\begin{array}{c}1.7 \\
(1.4,2.0)\end{array}$ & $\begin{array}{c}1.5^{\mathrm{b}} \\
(1.2,1.9)\end{array}$ & $\begin{array}{c}0.8^{\mathrm{b}} \\
(0.5,1.2)\end{array}$ & $\begin{array}{c}0.3^{\mathrm{b}} \\
(0.0,0.5)\end{array}$ & $\begin{array}{c}0.0^{\mathrm{b}} \\
(-0.1,0.2)\end{array}$ \\
\hline Reheated & Parboiled & $\begin{array}{c}83.5^{\mathrm{b}} \\
(63.4,103.6)\end{array}$ & $\begin{array}{c}4.8 \\
(4.7,5.0)\end{array}$ & $\begin{array}{c}0.6^{\mathrm{b}} \\
(0.4,0.8)\end{array}$ & $\begin{array}{c}1.9 \\
(1.5,2.3)\end{array}$ & $\begin{array}{c}1.6^{\mathrm{b}} \\
(1.2,2.0)\end{array}$ & $\begin{array}{c}0.7^{\mathrm{b}} \\
(0.3,1.1)\end{array}$ & $\begin{array}{c}0.0^{\mathrm{b}} \\
(-0.1,0.2)\end{array}$ & $\begin{array}{c}0.0^{\mathrm{b}} \\
(-0.2,0.2)\end{array}$ \\
\hline
\end{tabular}

Note: $95 \%$ confidence intervals $(\mathrm{CI})$ for each mean of blood glucose responses $(\mathrm{mmol} / \mathrm{L})$ are in brackets. The means in the same column with the different letter are significantly different $(p<0.05)$.

\subsection{Chewing Time and Proportions of Particle Size Distributions}

The majority of the chewed rice was either smaller than $425 \mu \mathrm{m}(\sim 47 \%)$ or larger than $2000 \mu \mathrm{m}$ $(\sim 44 \%)$ (Table 2$)$. Chewing time and particle sizes varied widely among individuals but insignificantly among treatments and within individual $(\mathrm{F}=2.966 ; p=0.057)$. The average chewing time required for reheated parboiled rice (33.1 s (95\% CI: 32.1, 34.1)) was $6.3 \mathrm{~s}$ longer than it was for the freshly cooked medium-grain white rice (26.8 s (95\% CI: 26.3, 27.3), $p=0.026)$ and $5.3 \mathrm{~s}$ longer than freshly cooked parboiled rice (27.8 s (95\% CI: $27.2,28.4), p=0.723)$. However, the only statistically significant 
difference $(p=0.026)$ was between reheated parboiled and freshly cooked medium-grain white rice. Chewing time (s) was negatively correlated with glycaemic responses (iAUC) for all rice samples $(\beta$ coefficient $=-2.360(p=0.089)$ for freshly cooked medium-grain white rice, $\beta$ coefficient $=-1.076$ $(p=0.055)$ for freshly cooked parboiled rice, and $\beta$ coefficient $=-0.946(p<0.001)$ for reheated parboiled rice).

Table 2. Before-swallowing rice particle size distribution $(\%)$ and chewing time $(\mathrm{s}) .(N=28)$ Values are mean and standard deviation, unless otherwise stated.

\begin{tabular}{|c|c|c|c|}
\hline Masticated Particle Size & $\begin{array}{c}\text { Freshly Cooked } \\
\text { Medium-Grain White }\end{array}$ & $\begin{array}{c}\text { Freshly Cooked } \\
\text { Parboiled }\end{array}$ & Reheated Parboiled \\
\hline $\begin{array}{l}\text { Particle Size Distributions } \\
\text { (\% by Weight) }\end{array}$ & $\begin{array}{c}\text { Mean }(95 \% \text { CI }) \\
\text { [Range of Particle Sizes (\%)] }\end{array}$ & & \\
\hline$>2000 \mu \mathrm{m}$ & $\begin{array}{c}46.1(44.9,47.3) \\
{[0.5-71.2]}\end{array}$ & $\begin{array}{c}44.0(43.1,44.9) \\
{[21.4-74.1]}\end{array}$ & $\begin{array}{c}42.6(41.4,43.8) \\
{[17.2-83.6]}\end{array}$ \\
\hline$<2000 \mu \mathrm{m} \sim>1400 \mu \mathrm{m}$ & $\begin{array}{c}2.9(2.8,3.0)^{\mathrm{a}} \\
{[0.3-5.8]}\end{array}$ & $\begin{array}{c}4.4(4.3,4.5)^{b} \\
{[1.5-7.7]}\end{array}$ & $\begin{array}{c}4.9(4.7,5.1)^{b} \\
{[0.9-8.5]}\end{array}$ \\
\hline$<1400 \mu \mathrm{m} \sim>425 \mu \mathrm{m}$ & $\begin{array}{c}3.1(3.0,3.2)^{\mathrm{a}} \\
{[1.2-6.1]}\end{array}$ & $\begin{array}{c}4.6(4.4,4.8)^{\mathrm{b}} \\
{[1.4-9.4]}\end{array}$ & $\begin{array}{c}5.3(5.1,5.5)^{b} \\
{[0.3-12.6]}\end{array}$ \\
\hline$<425 \mu \mathrm{m}$ & $\begin{array}{c}47.9(46.8,49.0) \\
\quad[25.0-96.7]\end{array}$ & $\begin{array}{c}47.0(46.1,47.9) \\
{[17.0-73.0]}\end{array}$ & $\begin{array}{c}47.8(46.6,49.0) \\
\quad[10.9-70.8]\end{array}$ \\
\hline \multirow[t]{2}{*}{ Chewing time (s) } & Mean $(95 \% \mathrm{CI})$ & & \\
\hline & $26.8(26.3,27.3)^{a}$ & $27.8(27.2,28.4)$ & $33.1(32.1,34.1)^{b}$ \\
\hline
\end{tabular}

ANOVA test. $p$-value with * $(<0.05)$ indicates that the mean in the same row is significantly different from others. The means with the different letter in the same row indicates a significant difference between these two means $(p<0.05)$.

For each rice sample, the proportion (\%) of the small size particles (between $2000 \mu \mathrm{m}$ and $425 \mu \mathrm{m}$ ) was positively correlated with chewing time (s) (coefficient $=337.4$ for freshly cooked medium-grain white rice $(p<0.001)$, coefficient $=248.2$ for freshly cooked parboiled rice $(p=0.001)$, and coefficient $=298.2$ for reheated parboiled rice $(p=0.008)$ ) (Table 3). The proportions of big particle size (over $2000 \mu \mathrm{m}$ ) of reheated parboiled rice were significantly inversely correlated with chewing time (coefficient $=-43.6(p=0.005)$ ), while no significant correlations were found in freshly cooked parboiled and medium-grain white rice (Table 3).

Table 3. Correlations between particle size distributions (\%) (as dependent variable) and chewing time (s) (as explanatory variable) $(N=28)$ by multiple linear regression analysis.

\begin{tabular}{|c|c|c|c|c|c|}
\hline $\begin{array}{c}\text { Rice Sample Particle } \\
\text { Size }(\mu \mathrm{m})\end{array}$ & Coefficient & Constant & $\mathbf{R}$ & F-Value & $p$-Value ${ }^{1}$ \\
\hline Medium-grain wite & \multicolumn{5}{|c|}{ Freshly cooked medium-grain white } \\
\hline$>2000 \mu \mathrm{m}$ & -13.985 & 33.197 & 0.307 & 2.701 & 0.112 \\
\hline$<2000 \mu \mathrm{m} \sim>1400 \mu \mathrm{m}$ & 168.442 & 21.859 & 0.367 & 4.057 & 0.050 * \\
\hline$<1400 \mu \mathrm{m} \sim 425 \mu \mathrm{m}$ & 337.431 & 16.178 & 0.649 & 18.871 & $<0.001 *$ \\
\hline$<425 \mu \mathrm{m}$ & 10.365 & 21.789 & 0.220 & 1.326 & 0.260 \\
\hline Test rice 1 & \multicolumn{5}{|c|}{ Freshly cooked parboiled } \\
\hline$>2000 \mu \mathrm{m}$ & -32.266 & 41.963 & 0.435 & 6.052 & 0.021 \\
\hline$<2000 \mu \mathrm{m} \sim>1400 \mu \mathrm{m}$ & 309.665 & 14.204 & 0.624 & 16.555 & $<0.001$ * \\
\hline$<1400 \mu \mathrm{m} \sim>425 \mu \mathrm{m}$ & 248.154 & 16.396 & 0.583 & 13.373 & $0.001 *$ \\
\hline$<425 \mu \mathrm{m}$ & 16.946 & 19.785 & 0.234 & 1.504 & 0.231 \\
\hline Test rice 2 & \multicolumn{5}{|c|}{ Reheated parboiled } \\
\hline$>2000 \mu \mathrm{m}$ & -43.571 & 51.654 & 0.516 & 9.449 & $0.005^{*}$ \\
\hline$<2000 \mu \mathrm{m} \sim>1400 \mu \mathrm{m}$ & 112.205 & 28.286 & 0.149 & 0.592 & 0.449 \\
\hline$<1400 \mu \mathrm{m} \sim 425 \mu \mathrm{m}$ & 298.233 & 17.178 & 0.490 & 8.197 & $0.008 *$ \\
\hline$<425 \mu \mathrm{m}$ & 40.906 & 13.557 & 0.457 & 6.880 & 0.014 * \\
\hline
\end{tabular}

1 ANOVA test for multiple linear regression and residue. $p$-value with ${ }^{*}(<0.05)$ indicates there is a significant linear relationship between particle size distribution and chewing time (s).

\subsection{Satiety and Palatability Responses (VAS Scores) over $120 \mathrm{~min}$}

The satiety responses to the three rice samples were not significantly different. However, participants who had reheated parboiled rice felt hungry approximately $30 \mathrm{~min}$ later than the other 
two freshly cooked rice products (medium-grain white and parboiled; $\mathrm{F}=3.281, p=0.043$ ) (Figure 2a). At $60 \mathrm{~min}$, the VAS scores of "How hungry do you feel?" for reheated parboiled rice was $1.3 \mathrm{~cm}$ $(95 \%$ CI: $0.16,2.4)$ lower than freshly cooked medium-grain white rice $(p=0.026)$ and $1.2 \mathrm{~cm}$ lower than freshly cooked parboiled rice $(p=0.033)$. No other significant differences for the desirability of sweet, salty, savoury, fatty, or other satiety questions were found (Figure 2). Simple linear regression analysis showed no association between any of the mean satiety scores and the blood glucose concentration, nor between satiety and chewing.

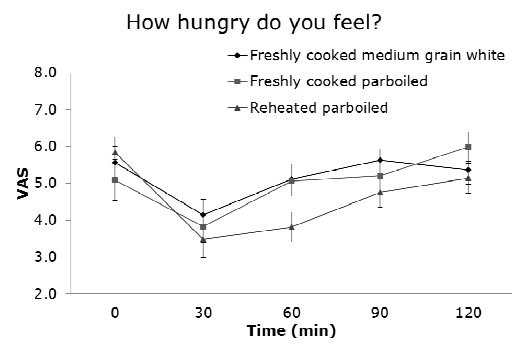

(a)

How full do you feel?

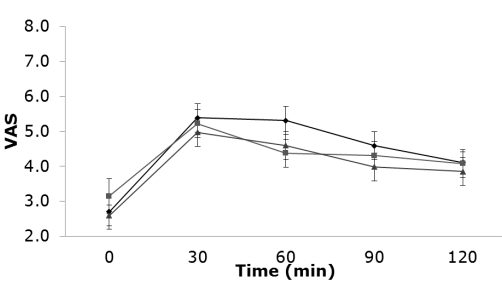

(c)

Want to eat something sweet?

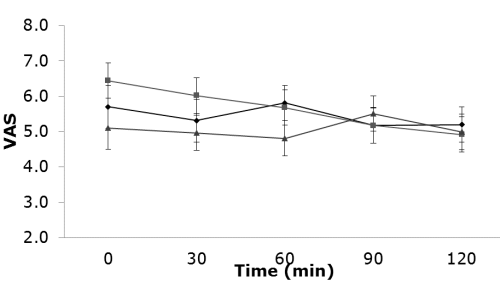

(e)

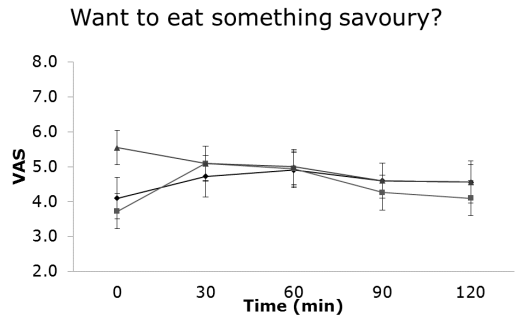

(g)

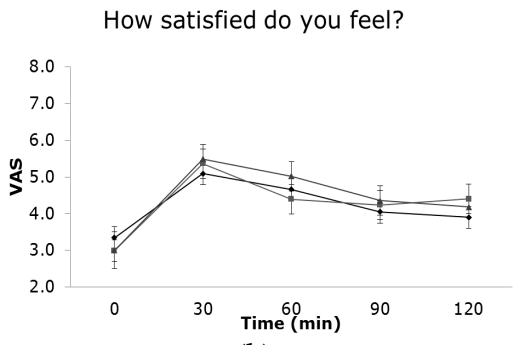

(b)

How much do you think you can

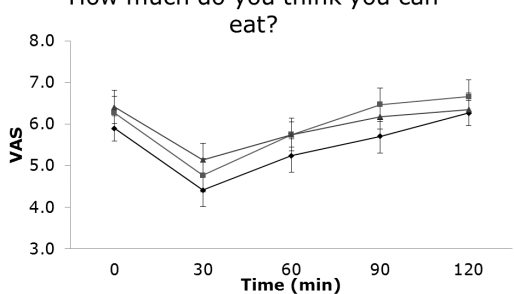

(d)

Want to eat something salty?

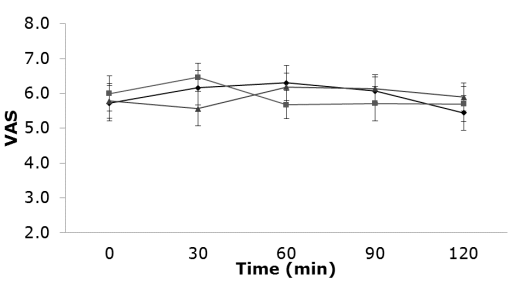

(f)

Want to eat something fatty?

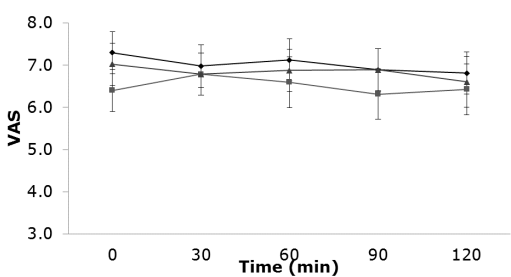

(h)

Yes, very
much

No, not at all

(i)

Figure 2. Mean satiety scores (VAS, visual analogue scale scores) change over $120 \mathrm{~min}$ for freshly cooked medium-grain white rice, freshly cooked parboiled rice and reheated parboiled rice, and each satiety VAS question: (a) "How hungry do you feel?"; (b) "How satisfied do you feel?"; (c) "How full do you feel?"; (d) "How much do you think you can eat?"; (e) "Want to eat something sweet?"; (f) "Want to eat something salty?"; (g) "Want to eat something savoury?"; (h) "Want to eat something fatty?"; (i) Line scaling for measuring participants' satiety on a $10 \mathrm{~cm}$ visual analogue scale (VAS). Error bars show the standard error of the mean VAS score. 
Reheated parboiled rice showed generally higher palatability scores than the other two freshly cooked meals (Figure 3). The visual appearance of reheated parboiled rice score was around 2.0 times higher than freshly cooked medium-grain white rice $(p<0.001)$ and 1.7 times higher than freshly cooked parboiled rice $(p=0.003)$. The smell of reheated parboiled rice was preferred to the other two freshly cooked rice meals (around 1.0 times higher than the control rice $(p=0.034)$ and around 1.0 times higher than the freshly cooked parboiled rice $(p=0.029))$. The parboiled rice taste scored around 1.5 times higher than freshly cooked medium-grain white rice $(p=0.023)$. However, no significant differences were found in the palatability of the aftertaste. Overall, reheated parboiled rice was preferred compared with medium-grain white rice $(p=0.003)$ and freshly cooked parboiled rice $(p=0.012)$.

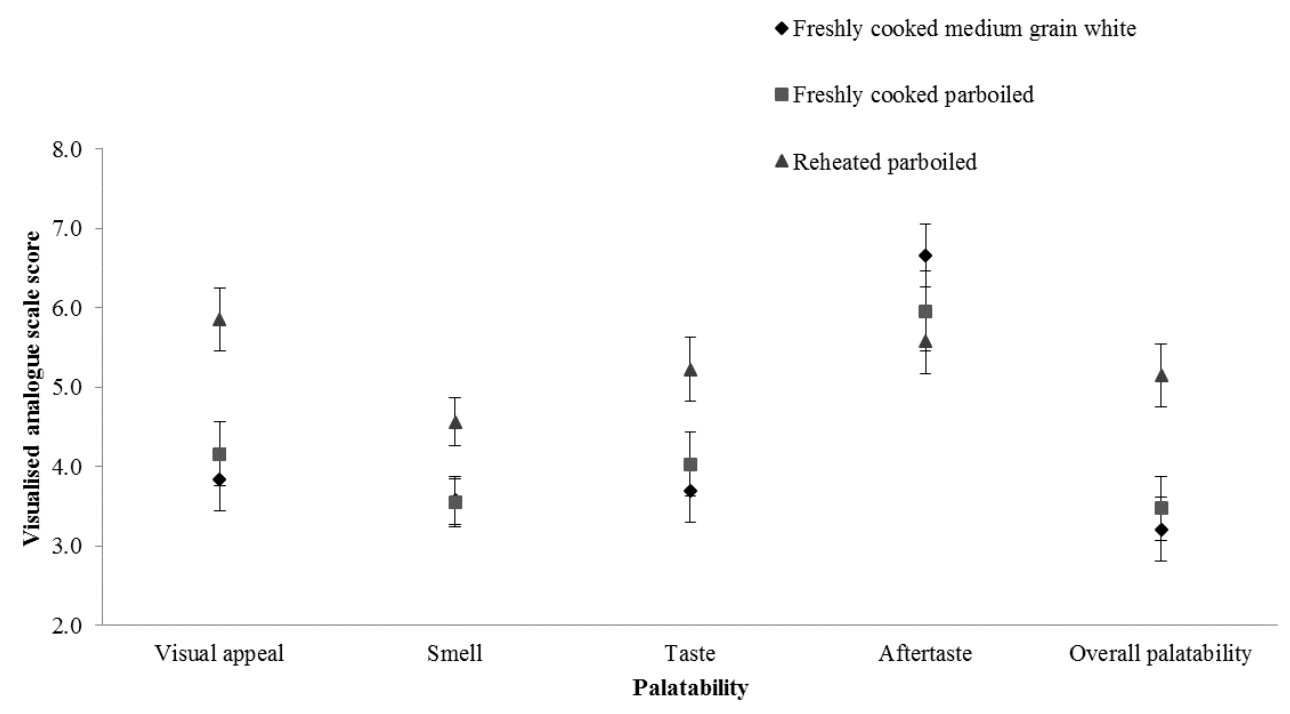

Figure 3. Mean palatability scores (VAS, visualised analogue scales scores) immediately after finishing eating prepared control and test rice samples (freshly cooked medium-grain white rice, freshly cooked parboiled rice and reheated parboiled rice) for each palatability VAS question.

\section{Discussion}

Twenty-four hours' cold storage and then reheating of cooked parboiled rice resulted in 1.7-fold $(p<0.001)$ lower blood glucose concentration trajectories over two hours than freshly cooked medium-grain white rice. Chewing time for $10 \mathrm{~g}$ cold-stored parboiled rice was $6 \mathrm{~s}(25 \%)$ longer and was considered more palatable, visually appealing and better tasting than freshly cooked medium-grain rice (all $p<0.05)$.

Others have reported a reduction in glucose trajectory with extent of parboiling [14] and consumers reheating cooked rice [25]. The role of the parboiling and cold storage in relation to reduced glycaemic response may be explained by the considerably higher proportion (approximately $30 \%$ higher) of RS in reheated parboiled rice than in freshly cooked medium-grain white rice reported in an in vitro experiment [12]. Parboiling pre-treatment and cold storage preparation method are associated with specific changes to the physico-chemical properties of the rice (i.e., rice starch retrogradation that increased the amylopectin and amylose crystallisation) and thus reduced the starch digestibility [26] and glycaemic responses [27]. It is suggested that cold storage significantly increased the amylose and amylopectin crystallisation [10] and enhanced its resistance to digestion [11] although the difference in the glycaemic trajectory for parboiled rice between fresh and reheated was not statistically significant.

The effect of cold storage and reheating on reducing glycaemic responses of parboiled rice was not significant in this study compared with freshly cooked parboiled rice. The systematic review by Boers et al. [27] indicated that multiple heating-cooling cycles can achieve a high RS content. In this 
study, only one heating-cooling cycle was applied. Boers et al. [25] also indicated that increasing RS in rice varieties by up to ten times did not have an effect on GI. The review also suggested that the change in RS content following heating-cooling cycles was insufficient (possibly due to the small differences in amylose content in rice varieties) to observe a significant change in glucose response or GI [25]. Also, the reheating (to $65^{\circ} \mathrm{C}$ ) might have reversed the retrogradation by breaking some of the amylopectin crystallites [12], and thus, lessening the impact on any possible reduction in glycaemic responses.

A mouthful of reheated parboiled rice was chewed for $6 \mathrm{~s}$ longer than the freshly cooked rice and there was a significant negative correlation between the proportion of large particle size $(>2000 \mu \mathrm{m})$ and chewing time. Although the degree of habitual mastication and the time of chewing required for preparing a food suitable for swallowing varied considerably among participants, they were relatively constant within individuals as previously reported [16]. The degree of habitual mastication (i.e., particle sizes) and the chewing time required for mastication depends on the food type, the saliva flow and the ability to form a cohesive, liquid coated bolus that can be swallowed [28]. Masticated rice with a higher proportion of RDS has been reported to form a bolus more easily than those with a lower proportion of RDS [16]. Cold storage promoted the retrogradation of rice starch (i.e., higher proportion of RS) and increased the hardness of the rice grain (i.e., change in texture after parboiling and cold storage), which, in turn, would prolong the chewing time for each mouthful [12].

As hypothesised based on the in vitro results [12], thorough mastication (i.e., increased chewing time) breaks rice grains into smaller particle sizes, increases the mixing of rice particles with salivary enzymes, improves hydrolysis of starch in mouth and stomach and, thus, is expected to increase the acute glycaemic response. Surprisingly, an inverse association between chewing time and postprandial glucose response was found. Others have also found that a longer chewing time is associated with the slower glycaemic response [18,29]. In 2005, Suzuki et al. [30] found that the insulin-impaired participants showed a greater glycaemic response after shorter chewing time compared with participants with normal insulin tolerance and extended chewing time, which confirmed that the degree of chewing might have a direct and positive effect on the rate of in vivo digestion and the glycaemic response.

One theory is that increasing chewing time can increase both the time of the food in oral cavity and oral amylase action $[18,29]$. It was proposed in some studies that the glucose release from starch digestion in oral cavity might also induce vagal activation and result in early insulin secretion (i.e., preabsorptive insulin or cephalic phase of insulin secretion) and thus reduced glycaemia [29]. Another theory is that more thorough mastication (i.e., longer chewing time) and swallowing a food bolus with fine particles $(<2000 \mu \mathrm{m})$ may delay gastric emptying and thus reduce postprandial glycaemia $[6,29,31]$. A bolus with finer particles reduces the viscosity of gastric content and increases pyloric outflow, thus increases sedimentation of solids in liquids, and promotes the ability of the antrum to preferentially empty liquids faster than solids [28]. The increasing interaction between macronutrients, such as starch molecules, amylopectin, and amyloses, and the receptors within the small intestine, promotes the stimulation of the vagus nerve and the secretion of insulin and gut hormones (GLP-1, CCK, and PYY) from entero-endocrine cells while suppressing glucagon, shortens the subsequent gastric emptying, and thus, reduces postprandial blood glucose [31].

Few studies have investigated the effect of rice with differenct starch digestibility profiles on appetite. Zenel et al. found that participants were significantly more hungry at $30 \mathrm{~min}$ after high amylose rice with higher RS content compared to low amylose rice with lower RS [32]. In a study by Chiu et al., it was reported that there was no significant difference in appetite between short-grain rice and high RS rice in healthy adults [33]. In this study, the only significant difference in appetite scores was observed at $60 \mathrm{~min}$, when the participants reported feeling less hungry after consuming reheated parboiled rice than after freshly cooked parboiled and medium-grain white rice. A recent systematic review further suggested that longer chewing may decrease self-reported hunger and possibly alter the gut hormone response related to satiety [34]. However, we did not find an effect on satiety of reheating the parboiled rice compared to the other two rice samples despite the significantly different 
iAUC of blood glucose responses. Participants preferred the reheated parboiled rice compared to the other two samples for visual appeal, smell and taste.

One strength of this study is that it followed the cold storage and reheating method from the New Zealand Food Safety Authority guidelines, which has indicated the safe practice of preparing boiled rice to stop Bacillus cereus growth during storage and stop toxin production. The cooked rice may be kept for a short time at more than $60^{\circ} \mathrm{C}$ or cooled quickly and stored for up to one day [35]. The Ministry for Primary Industries [19] advised that cooked rice should be removed from the hot container and spread into a clean shallow container $(<10 \mathrm{~cm}$ deep) and then placed in a refrigerator at $4{ }^{\circ} \mathrm{C}$ or lower to be cooled quickly and evenly to prevent bacteria growth and toxin production. It is required to evenly reheat the cold-stored rice to over $65^{\circ} \mathrm{C}$ to destroy the bacteria and production of toxins.

Another strength of this study is that it followed a glycaemic response method whose precision and validity were tested and validated by previous studies. The group of participants consumed a serving of each rice sample on separate experiment days (seven days apart) to minimise possible intra-individual variation and to improve precision. On each experiment day, the volumes of the test meals were similar, the time spent on consuming the meals was restricted to less than five minutes, all rice meals were fully gelatinised, and the rice grains all retained their original shape when they were served to participants to minimise the influences on glycaemic response and satiating power of each rice meal.

Limitations of the study include that each condition, including the chewed sample, was measured only once. Participant compliance was high and all participants completed all measurements. However, this relatively small study is only applicable to these specific brands of rice cooked in this specific way. It should be acknowledged that the volunteers may not necessarily be representative of the population at large that some unrecognized attributes of this convenience sample could explain the marked differences in glycaemic responses among three rice samples. Variation among the brands or rice (such as rice origin, storage time/condition, and humidity) and the methods of cooking also needs to be explored further with more participants to be powered to find further influences. The two factors that might have affected the gastric emptying rate, glycaemic response, and the feelings of satiety and palatability are the chewed particle size and the net energy of the rice meals served to each participant. Although chewed particle size is impossible to control, the net energy may be monitored by dietary measurements in order to explain changes in the subjective satiety score in the future.

\section{Conclusions}

Compared with freshly cooked white rice, reheated cold-stored parboiled rice and freshly cooked parboiled rice reduced the postprandial glycaemic response and extended the chewing time. No significant difference in postprandial glycaemic response was observed between freshly cooked and reheated parboiled rice samples. The reheated parboiled rice was preferred due to improved palatability. For regular consumers of parboiled rice, preferably reheating cooked rice after cold storage would lower the dietary glycaemic load and, in the long term, may reduce the risk for type 2 and gestational diabetes. More trials are needed.

Acknowledgments: The study was funded by Faculty of Health and Environmental Sciences, Auckland University of Technology.

Author Contributions: Louise Weiwei Lu conceptualized and drafted the manuscript. The Human Nutrition GI Service Team at University of Otago, led by Bernard Venn, assisted in the study design, participants' recruitment, and data collection. Elaine Rush, John Monro and Jun Lu provided critical input on the synthesis across experiments and the final manuscript.

Conflicts of Interest: There is no conflict of interest. This article does not contain any studies with human or animal subjects. 


\section{References}

1. Parackal, S.M.; Smith, C.; Parnell, W.R. A profile of New Zealand 'Asian' participants of the 2008/09 Adult National Nutrition Survey: Focus on dietary habits, nutrient intakes and health outcomes. Public Health Nutr. 2015, 18, 893-904. [CrossRef] [PubMed]

2. Englyst, K.; Liu, S.; Englyst, H.N. Nutritional characterization and measurement of dietary carbohydrates. Eur. J. Clin. Nutr. 2007, 61, S19-S39. [CrossRef] [PubMed]

3. Burton, P.M.; Monro, J.A.; Alvarez, L.; Gallagher, E. Glycemic Impact and Health: New Horizons in White Bread Formulations. Crit. Rev. Food Sci. Nutr. 2011, 51, 965-982. [CrossRef] [PubMed]

4. Wolever, T.; Jenkins, A. Analysis of glycemic index methodology. J. AOAC Int. 2010, 93, 29A. [PubMed]

5. Grundy, S. Pre-diabetes, metabolic syndrome, and cardiovascular risk. J. Am. Coll. Cardiol. 2012, 59, 635-643. [CrossRef] [PubMed]

6. Phillips, L.; Deane, A.; Jones, K.; Rayner, C.; Horowitz, M. Gastric emptying and glycaemia in health and diabetes mellitus. Nat. Rev. Endocrinol. 2015, 11, 112-128. [CrossRef] [PubMed]

7. Zhu, Y.; Hsu, W.; Hollis, J. The impact of food viscosity on eating rate, subjective appetite, glycemic response and gastric emptying rate. PLoS ONE 2013, 8, e67482. [CrossRef] [PubMed]

8. Tamura, M.; Singh, J.; Kaur, L.; Ogawa, Y. Impact of structural characteristics on starch digestibility of cooked rice. Food Chem. 2016, 191, 91-97. [CrossRef] [PubMed]

9. Tan, V.; Ooi, D.; Kapur, J.; Wu, T.; Chan, Y.; Henry, C.; Lee, Y. The role of digestive factors in determining glycemic response in a multiethnic Asian population. Eur. J. Nutr. 2015, 1-9. [CrossRef] [PubMed]

10. Sajilata, M.; Singhal, R.; Kulkarni, P. Resistant starch—A review. Compr. Rev. Food Sci. Food Saf. 2006, 5, 1-17. [CrossRef]

11. Riva, M.; Fessas, D.; Schiraldi, A. Starch retrogradation in cooked pasta and rice. Cereal Chem. 2000, 77, 433-438. [CrossRef]

12. Lu, L.; Monro, J.; Lu, J.; Rush, E. Effect of Cold Storage, Reheating, and Particle Sizes on In Vitro Glucose Release and Starch Digestibility among Five Rice Products in Auckland, New Zealand. J. Rice Res. 2016, $4,171$.

13. Wolever, T.M.; Jenkins, D.J. The use of the glycemic index in predicting the blood glucose response to mixed meals. Am. J. Clin. Nutr. 1986, 43, 167-172. [PubMed]

14. Larsen, H.; Rasmussen, O.; Rasmussen, P.H.; Alstrup, K.; Biswas, S.; Tetens, I.; Thilsted, S.; Hermansen, K. Glycaemic index of parboiled rice depends on the severity of processing: Study in type 2 diabetic subjects. Eur. J. Clin. Nutr. 2000, 54, 380-385. [CrossRef] [PubMed]

15. Chitra, M.; Singh, V.; Ali, S.Z. Effect of processing paddy on digestibility of rice starch by in vitro studies. J. Food Sci. Technol. 2010, 47, 414-419. [CrossRef] [PubMed]

16. Ranawana, V.; Monro, J.; Mishra, S.; Henry, C. Degree of particle size breakdown during mastication may be a possible cause of interindividual glycemic variability. Nutr. Res. 2010, 30, 246-254. [CrossRef] [PubMed]

17. Ranawana, V.; Leow, M.; Henry, C. Mastication effects on the glycaemic index: Impact on variability and practical implications. Eur. J. Clin. Nutr. 2014, 68, 137-139. [CrossRef] [PubMed]

18. Kataoka, M.; Venn, B.; Williams, S.; Te Morenga, L.; Heemels, I.; Mann, J. Glycaemic responses to glucose and rice in people of Chinese and European ethnicity. Diabet. Med. 2013, 30, e101-e107. [CrossRef] [PubMed]

19. Ministry for Primary Industries. Safe Cooling of Cooked Rice. Available online: http:/ /www.foodsafety. govt.nz/elibrary/industry/safe_cooling-cooked_rice.htm (accessed on 9 May 2017).

20. Venn, B.; Wallace, A.; Monro, J.; Perry, T.; Brown, R.; Frampton, C.; Green, T. The glycemic load estimated from the glycemic index does not differ greatly from that measured using a standard curve in healthy volunteers. J. Nutr. 2006, 136, 1377-1381. [PubMed]

21. Venn, B.; Green, T. Glycemic index and glycemic load: Measurement issues and their effect on diet-disease relationships. Eur. J. Clin. Nutr. 2007, 61, 122-131. [CrossRef] [PubMed]

22. Parker, B.; Sturm, K.; MacIntosh, C.; Feinle, C.; Horowitz, M.; Chapman, I. Relation between food intake and visual analogue scale ratings of appetite and other sensations in healthy older and young subjects. Eur. J. Clin. Nutr. 2004, 58, 212-218. [CrossRef] [PubMed]

23. Diabetes New Zealand. Lab Tests \& Type 2 Diabetes. Available online: http://www.diabetes.org.nz/living well_with_diabetes/living_with_type_2_diabetes/lab_tests (accessed on 9 May 2017). 
24. Brouns, F.; Bjorck, I.; Frayn, K.N.; Gibbs, A.L.; Lang, V.; Slama, G.; Wolever, T.M. Glycaemic index methodology. Nutr. Res. Rev. 2005, 18, 145-171. [CrossRef] [PubMed]

25. Boers, H.; ten Hoorn, J.; Mela, D. A systematic review of the influence of rice characteristics and processing methods on postprandial glycaemic and insulinaemic responses. Br. J. Nutr. 2015, 114, 1035-1045. [CrossRef] [PubMed]

26. Derycke, V.; Vandeputte, G.; Vermeylen, R.; De Man, W.; Goderis, B.; Koch, M.; Delcour, J. Starch gelatinization and amylose-lipid interactions during rice parboiling investigated by temperature resolved wide angle X-ray scattering and differential scanning calorimetry. J. Cereal Sci. 2005, 42, 334-343. [CrossRef]

27. Heinemann, R.; Fagundes, P.; Pinto, E.; Penteado, M.; Lanfer-Marquez, U. Comparative study of nutrient composition of commercial brown, parboiled and milled rice from Brazil. J. Food Compos. Anal. 2005, 18, 287-296. [CrossRef]

28. Bornhorst, G.; Singh, R. Bolus formation and disintegration during digestion of food carbohydrates. Compr. Rev. Food Sci. Food Saf. 2012, 11, 101-118. [CrossRef]

29. Madhu, V.; Shirali, A.; Pawaskar, P.; Madi, D.; Chowta, N.; Ramapuram, J. Mastication Frequency and Postprandial Blood Sugar Levels in Normoglycaemic and Dysglycaemic Individuals: A Cross-Sectional Comparative Study. J. Clin. Diagn. Res. 2016, 10, OC06. [CrossRef] [PubMed]

30. Suzuki, H.; Fukushima, M.; Okamoto, S.; Takahashi, O.; Shimbo, T.; Kurose, T.; Yamada, Y.; Inagaki, N.; Seino, Y.; Fukui, T. Effects of thorough mastication on postprandial plasma glucose concentrations in nonobese Japanese subjects. Metabolism 2005, 54, 1593-1599. [CrossRef] [PubMed]

31. Marathe, C.; Rayner, C.; Jones, K.; Horowitz, M. Relationships between gastric emptying, postprandial glycemia, and incretin hormones. Diabetes Care 2013, 36, 1396-1405. [CrossRef] [PubMed]

32. Zenel, A.M.; Stewart, M.L. High amylose white rice reduces post-prandial glycemic response but not appetite in humans. Nutrients 2015, 7, 5362-5374. [CrossRef] [PubMed]

33. Chiu, Y.-T.; Stewart, M.L. Effect of variety and cooking method on resistant starch content of white rice and subsequent postprandial glucose response and appetite in humans. Asia Pac. J. Clin. Nutr. 2013, 22, 372-379. [PubMed]

34. Miquel-Kergoat, S.; Azais-Braesco, V.; Burton-Freeman, B.; Hetherington, M. Effects of chewing on appetite, food intake and gut hormones: A systematic review and meta-analysis. Physiol. Behav. 2015, 151, 88-96. [CrossRef] [PubMed]

35. Lake, R.; Hudson, A.; Cressey, P. Risk Profile: Bacillus Spp. in Rice; Institute of Environmental Science \& Research Limited: Christchurch, New Zealand, 2004. 